\title{
STONE TOOL-USE EXPERIMENTS TO DETERMINE THE FUNCTION OF GRINDING STONES AND DENTICULATE SICKLES
}

\author{
Richard Fullagar ${ }^{1}$, Li Liu ${ }^{2}$, Sheahan Bestel $^{3}$, Duncan Jones ${ }^{4}$, Wei Ge ${ }^{4}$ \\ Anthony Wilson ${ }^{4}$ and Shaodong Zhai ${ }^{4}$ \\ ${ }^{1}$ Centre for Archaeological Science, University of Wollongong; and Scarp Archaeology, richard.fullagar@scarp.com.au \\ ${ }^{2}$ Stanford University, California, USA, liliu@stanford.edu \\ ${ }^{3}$ Department of Anthropology, University of Toronto at Mississauga, Ontario, Canada \\ ${ }^{4}$ La Trobe University, Melbourne, Victoria Australia \& Monash University, Melbourne, Australia
}

\begin{abstract}
Within a broader study of early Chinese agriculture, stone tool-use experiments were undertaken to document usewear on sandstone and tuff implements used to process Quercus acorns, Avena oats and Setaria millet. In other experiments, we examined usewear on denticulate slate sickles used to harvest Quercus acorns, Poaceae grass and Typha reeds. Results support other studies that indicate different patterns of abrasive smoothing, striation formation and polish development together provide a basis for distinguishing some of these tasks. This research is aimed to establish a database for functional analysis of grinding stones and sickles from the early Neolithic Peiligang culture. Controlled experiments are required to identify critical variables (e.g. silica in husks) that affect usewear patterns.
\end{abstract}

\section{INTRODUCTION}

Distinctive stone tools in Early Neolithic China include grinding stones called mopan (lower grinding stone) and mobang (upper grinding stone or handstone) and denticulate slate sickles (Figure 1). It is the subject of ongoing research to determine the technological variability, functions and associations of such tools in a variety of archaeological settings. However, previous studies (e.g. Chen 2002, Liu 2008, Song 1997, Wu 1986) have proposed that particular plant foods may have been associated with these implements. For example, slate sickles with edgeground denticulations may have been used to harvest grain or other produce and the mopan and mobang may have been used for grinding the harvested food (e.g. grain, acorns or other nuts/fruit) prior to cooking. An initial research objective has been to evaluate the potential of usewear to determine diagnostic patterns associated with processing different taxonomic classes (e.g. siliceous cereal grains vs. nuts). Aspects of this research include:

- Controlled experiments to identify critical variables (e.g. the role of silica in husks) associated with usewear formation. The identification of key variables is important for assessing overlapping wear patterns and multi-functionality (i.e. processing more than one kind of food).

- Replication of prehistoric tool forms (e.g. denticulate slate sickles) and subsequent tool-use experiments to evaluate whether particular taxa were effectively exploited using a specific technique and to compare usewear on experimental and archaeological tools.

- Integration of these data with residue studies to determine the function of specific implements (e.g. Liu et al 2010a, b).

In this paper we address the first two aspects with case studies from experimental grinding stone and sickles with ground-edge denticulations. We summarise usewear patterns potentially relevant for distinguishing prehistoric processing of Quercus acorns and cereal grain (Avena oats and Setaria millet). A particular interest has been to initiate investigation of multi-functional usewear on grinding stones (i.e. usewear on tools used for processing several different materials). In addition we examine usewear patterns on experimental denticulate sickles used for harvesting acorns, reeds and grasses. Grinding tool-use experiments are highly relevant for interpreting the usewear on both implement types. Although these studies are incomplete, it is possible to propose hypotheses about the nature of overlapping wear patterns on implements used for processing both cereal grain and acorns.

\section{METHODS}

In this study, we used experimental tools for harvesting and processing seeds and acorns. Two sets of tool-use experiments were undertaken. First, we undertook experiments to replicate usewear on stones used for grinding and processing a range of plant materials. Second, we manufactured denticulate sickles and undertook a range of experiments to evaluate their possible use to harvest plant resources. 


\begin{tabular}{|c|c|c|c|c|c|c|c|c|c|}
\hline & lower & hand & lower & hand & lower & hand & lower & hand & $\begin{array}{l}\text { Hand }=\text { Upper grinding stone } \\
\text { Lower = lower grinding stone }\end{array}$ \\
\hline $\begin{array}{l}\text { PVS } \\
\text { Peel }\end{array}$ & XS11 & XS18 & $\mathrm{XS12}$ & XS16 & XS13 & XS15 & XS14 & XS17 & Notes \\
\hline Peel A & $x$ & $x$ & $x$ & $X$ & $\mathrm{X}$ & $X$ & $X$ & $X$ & Unused surface \\
\hline Peel B & $x$ & $x$ & $x$ & $x$ & $x$ & $x$ & $x$ & $x$ & 15 minutes grinding rock on rock \\
\hline Peel C & $x$ & $X ?$ & $x$ & $X ?$ & $X$ & $X ?$ & X & $X ?$ & $\begin{array}{l}\text { Plus } 20 \text { minutes of grinding oats (with } \\
\text { husks) }\end{array}$ \\
\hline Peel D & & & $\underline{x}$ & & & & & & Unused surface: XS12 only \\
\hline Peel E & $X$ & $X ?$ & $\underline{X}$ & $X ?$ & $\mathrm{X}$ & $X ?$ & $x$ & $X ?$ & $\begin{array}{l}\text { Plus } 20 \text { minutes of grinding millet } \\
\text { (no husks) }\end{array}$ \\
\hline Peel F & & & $x$ & $X ?$ & $\underline{X}$ & $X ?$ & $x$ & $X ?$ & $\begin{array}{l}\text { Unused surface: XS12 and XS14 } \\
\text { Used (stone on stone) surface: XS13 }\end{array}$ \\
\hline Peel G & & & $x$ & $X ?$ & $\underline{\mathbf{X}}$ & $X ?$ & $x$ & $X ?$ & $\begin{array}{l}\text { XS12, XS14: Taken after } 20 \text { minutes } \\
\text { of grinding and pounding soaked } \\
\text { aged acorns (with husks) }\end{array}$ \\
\hline Peel $H$ & & & $x$ & $X ?$ & $\underline{x}$ & $X ?$ & $x$ & & Repeat of $G$ on dried surface \\
\hline
\end{tabular}

Table 1: PVS Peels from experimental grinding stones.

\begin{tabular}{|c|c|c|c|c|c|c|c|c|c|}
\hline Sample & $\begin{array}{l}{ }^{*} \text { Tool } \\
\text { stone }\end{array}$ & Unused & $\begin{array}{l}\text { Grinding } \\
\text { rock on } \\
\text { rock }\end{array}$ & $\begin{array}{c}\text { Plus } \\
\text { grinding } \\
\text { oats with } \\
\text { husks }\end{array}$ & $\begin{array}{l}\text { Plus grind- } \\
\text { ing millet } \\
\text { with no } \\
\text { husks }\end{array}$ & $\begin{array}{c}\text { Plus } \\
\text { grinding } \\
\text { acorns } \\
\text { with } \\
\text { husks }\end{array}$ & $\begin{array}{c}\text { Only } \\
\text { grinding } \\
\text { millet with } \\
\text { no husks }\end{array}$ & $\begin{array}{c}\text { Only } \\
\text { grinding } \\
\text { acorns } \\
\text { with } \\
\text { husks }\end{array}$ & $\begin{array}{l}\text { Grinding } \\
\text { rock on } \\
\text { rock plus } \\
\text { acorns } \\
\text { with } \\
\text { husks }\end{array}$ \\
\hline XS11 & $\begin{array}{c}\text { Aust. } \\
\text { mss }\end{array}$ & A & B & C & E & & & & \\
\hline XS18 & $\begin{array}{c}\text { China } \\
\text { mss }\end{array}$ & A & B & C & E & & & & \\
\hline XS12 & $\begin{array}{c}\text { China } \\
\text { mss }\end{array}$ & A, D & B,F & C & & & $E$ & G,H & \\
\hline XS16 & $\begin{array}{c}\text { China } \\
\text { mss }\end{array}$ & A & B & $C$ & & & $E$ & G.H & \\
\hline XS13 & $\begin{array}{c}\text { China } \\
\text { css }\end{array}$ & A & $\mathrm{B}, \mathrm{F}$ & $C$ & $E$ & H & & & $\mathrm{G}, \mathrm{H}$ \\
\hline XS15 & $\begin{array}{c}\text { China } \\
\text { mss }\end{array}$ & A & B & $C$ & $E$ & G & & & \\
\hline XS14 & $\begin{array}{l}\text { China } \\
\text { tuff }\end{array}$ & A & $\mathrm{B}, \mathrm{F}$ & $C$ & $E$ & & & G,H & \\
\hline XS17 & $\begin{array}{c}\text { China } \\
\text { mss }\end{array}$ & A & B & C & $E$ & G & & & \\
\hline
\end{tabular}

Table 2: PVS Peels from experimental grinding stones grouped into tasks (mss = medium-grained sandstone, css $=$ coarse- grained sandstone)

\section{Grinding stone experiments}

The experimental slabs (XS), collected from China and Australia, were used in the controlled grinding experi- ments undertaken at La Trobe University (Figure 2). All handstones (labelled XS15-18, Figure 3) were similar medium-fine grained red-purple sandstone collected at Huizui, Henan Province, China (Webb et al. 2007). Poly- 
vinyl siloxane (PVS) "peels" provided durable and high resolution records of usewear after various phases of use (Tables 1 and 2).

Experimental lower grinding stones (labelled XS1114, see Tables 1 and 2) included:

- XS11: medium-grained light brown sandstone from Horsham, western Victoria, Australia (with handstone XS18), previously unused;

- XS12: medium-grained reddish-brown sandstone from China, Huizui (with handstone XS 16), previously unused;

- XS13: coarse-grained felspathic white sandstone from China, Huizui (with handstone XS 15), upper surface previously unused; lower surface previously used by Owen (2007) to grind a dolomite stone spade blank for 8-9 hours; and

- XS14: tuff from China, Zhejiang quarry (with handstone XS17), previously unused.

The experimental grinding stones were used to process Avena sp. oats, Setaria sp. millet and Quercus sp. acorns to a powder or paste (Figure 4). The acorns were soaked overnight (Figure 5) before pounding and grinding, in accordance with recommended food preparation practices, and processed while wet. Water was not added in any other experiments. Added water introduces a new usewear variable because water reacts with polishing agents to encourage polish development on siliceous surfaces (Fullagar 1991). Water also aids in dispelling dust and grit and probably speeds the polishing process (e.g. Owen 2007).

Periodically after each phase of use, experimental slab surfaces were brushed lightly (avoiding formation of new usewear) with ethanol to remove residues. PVS "peels" (labelled Peel A, Peel B, etc.) were taken as records of microscopic usewear on each upper and lower grinding stone during each phase of use (Figures 6-8). The first peel from each grinding stone (Peel A) documents the unused surface. Other peels are from surfaces at various later stages of the experiments (see Tables 1 and 2 below). All tools were hand used in one dominant direction and the tasks were carefully documented and timed (Figure 9). The planned sequence of tasks documents single and multiple overlapping usewear patterns.

Task 1: Experimental grinding of stone on stone

Stone on stone usewear (see Results below, Figure 10) is recorded on each Peel B (Table 1), taken after 15 minutes of grinding stone on stone from the same location as peel A. The stone on stone wear provides a basis for comparison with usewear from various other grinding tasks.

Task 2: Experimental grinding of Avena oats (with husks) The experimental slab was rotated 90 degrees (to distinguish striations from the earlier stone on stone wear), and each Peel C (from XS11, XS12, XS13, and XS14) was taken after 20 minutes of grinding Avena oats with husks attached (Tables 1 and 2). Consequently each peel $C$ represents accumulated usewear from stone on stone and grinding oats with husks (Tables 1 and 2). Aqueous residue samples were also removed to recover phytolith and starch residues but these are not discussed further.

Task 3: Experimental grinding of Setaria millet

Each Peel E was taken on XS11, XS13 and XS14 after 20 minutes of grinding Setaria millet (with husks) in the same location as Peel C (Tables 1 and 2). Consequently, each Peel E for XS11, XS13 and XS14 has accumulated usewear from grinding stone, oats with husks and millet with no husks (Table 2). Peel D from XS12 comes from an unused lower surface and Peel E from XS12 documents 20 minutes of grinding millet with no husks only (Tables 1 and 2). Experimental tools XS11 and XS18 were not used after this.

Task 4: Experimental grinding of Quercus acorns with husks

Peel $\mathrm{F}$ was taken to document unused surfaces on experimental tools XS12 and XS14 (Tables 1 and 2) before Peel $G$ was taken from the same location, after 20 minutes of grinding and pounding aged acorns that had been soaked overnight. However Peel F from XS13 comes from a surface previously polished (see Results below, Figure 12) from grinding a dolomite stone spade for eight hours. Peel $\mathrm{G}$ from this location on XS13 represents usewear from grinding and pounding aged and soaked acorns (with husks) on this previously used stone grinding surface (see results, Figure 12 below).

A further set of PVS peels (labelled Peel H) was taken from the same location as Peel G, (except for XS17) because moisture from grinding wet acorns caused defective records on the initial set (Peel G).

The PVS peels provide records of various combinations of usewear on the different tool stones. The handstone PVS peels provide records of accumulated usewear at the completion of each task on fresh and previously ground surfaces.

\section{Slate sickle experiments}

Three experimental sickles (XSK01, XSK02 and XSKO3) were manufactured to replicate the form of prehistoric denticulate sickles. One sickle (XSK04) was manufactured without a denticulate edge. Manufacturing and hafting techniques did not replicate prehistoric tool-use conditions but were designed to assess usewear formation and the effectiveness of the tool design. Sickles were shaped from locally available (Australian) slate with an anglegrinder (with abrasive disk) and the denticulations were made with a hand-held metal file. Sickles were hafted in a split wooden handle and secured with a bolt and wing nut (sees Results below, Figures 17, 20 and 23). 


\begin{tabular}{l|l|c|c|c|c}
\hline Sickle & Edge & Unused & $\begin{array}{l}30 \text { minutes } \\
\text { acorns }\end{array}$ & $\begin{array}{l}30 \text { minutes } \\
\text { reeds }\end{array}$ & $\begin{array}{l}30 \text { minutes } \\
\text { grass }\end{array}$ \\
\hline \hline XSK01 Side A & denticulate & A & C & & \\
XSK01 Side B & denticulate & B & D & & \\
XSK02 Side A & denticulate & A & & C & \\
XSK02 Side B & denticulate & B & & D & \\
XSK03 Side A & denticulate & A & & & C \\
XSK03 Side B & denticulate & B & & & D \\
XSK04 Side A & plain & A & & & C \\
XSK04 Side B & plain & B & & & D \\
\hline
\end{tabular}

Table 3: PVS Peels from experimental sickles, grouped into tasks.

After each phase of use, experimental sickles were brushed lightly (avoiding formation of new usewear) with ethanol to remove residues, and sets of PVS peels (labelled Peel A, B, C and D) were taken as records of microscopic usewear on each experimental sickle. Each Peel $A$ is from unused surface A and each Peel B is from unused surface B (Table 3). Peels C and D were taken from the same location during subsequent phases of use for each task (Table 3).

\section{Task 1: Harvesting Quercus Acorns,}

The experimental sickle XSK01, with a denticulate edge, was hafted at right angles to a long pole that was drawn down towards the harvester to strip acorns for 30 minutes (see Results below, Figure 16). The sickle was thus in contact with branches, leaves and acorn parts. It proved very effective in removing acorns efficiently.

\section{Task 2: Harvesting Typha reeds}

The experimental sickle XSK02, with a denticulate edge, was hafted at right angles to a short pole that was used for 30 minutes to cut a handful of reeds in a slicing motion towards the harvester (See Results below, Figure 19.) The sickle proved very effective in cutting the reeds.

\section{Task 3: Harvesting Poaceae grass}

The experimental sickle XSK03, with a denticulate edge, was hafted at right angles to a short pole that was used for 30 minutes to cut handfuls of grass in a slicing motion towards the harvester (see Results below, Figure 22). This proved to be much more effective than experimental sickle XSK04, which lacked a denticulate edge. The denticulate edge seems essential for the sickle blade to bite effectively into the grass stems. Experimental sickle XSK04 proved so ineffective that its use was discontinued.

\section{RESULTS}

The results of each experiment were documented and are summarised below.

\section{Grinding stone experiments}

All tools proved effective in processing the harvested products, although a pounding action was required in order to crush the oily acorn kernels both with husks attached and after husks had been dislodged. Grinding proved to be a highly effective action for processing the cereal grains with or without husks. The preferred mode of use (e.g. more pounding than grinding) and properties of the seeds and kernels are probably responsible for differential development of striations, which were more prevalent from grinding seeds, and pitting, which was more prevalent after pounding acorns.

Grinding stone on stone is consistent with previous work (e.g. Owen 2007; Cunnar 2007). Dominant usewear includes abundant, relatively deep striations with angular cross-section commonly visible in nearly all microscopic fields of view (Figure 11, left). Away from crystal faces the striations are still very common and give the surface a corrugated polished appearance. The degree of surface levelling and abundance of striations increased with time, although the corrugated appearance was retained in patches (Figure 12, left; Figure 13, left). A notable feature is that the lower parts of the topography remain unpolished. Despite grinding after 8 hours, the sandstone was continuously worn down as sand particles were plucked and gouged from the surface. Unlike tougher rocks like altered basalts, commonly used for making axes, the sandstone did not sustain a microscopically smooth developed polish.

Grinding oats with husks on the previously ground surface tended to gradually obliterate the coarse and relatively deep angular striations produced by the initial rock on rock grinding. New and finer striations are introduced and are recognised on images because our experiment rotated the orientation of the handstone and grinding stone by $90^{\circ}$ (Figure 12, right). In addition the surface away from quartz crystals tends to develop a more reticular (net like) polished surface where the lowest parts of the microtopography remain noticeably less polished than the higher parts, where there is more friction with the handstone. 
Phytoliths in husks are likely to introduce a polishing agent (in the form of amorphous silica) that enhances polish development which would be more marked if water were also added (Fullagar 1991). Without husks the polish is less developed.

After grinding oats with husks, use of the same tool to further grind another grain (millet with no husks) causes further surface levelling and more striations in the direction of use, but little further development of polish on the tool surface (Figure 13).

Grinding and pounding acorns produced noticeable differences in the type of polished surface. First, the lower parts of the micro-topography were much more polished than was sustained by the grinding of seeds (Figure 14, right). Second, striations were markedly less abundant and in fact quite rare except for scratches on quartz crystals, unless the surface had been previously ground (cf. Figures 13 and 14). Third, pitting was more common on acorn processing implements (Figure 15, right).

The relative contribution of husks and oil (in acorns and cereal seeds) to polish formation (perhaps as lubricants and polishing agents) needs further investigation, but mechanical processes are likely to be significant. In particular, the thicker soft acorn kernels undoubtedly buffer the impact of grinding/pounding stones. The relative contribution of pounding as opposed to grinding is also likely to increase the incidence of pitting associated with acorn processing.

\section{Slate sickle experiments}

The experimental sickle XSK04 with no denticulations along the edge proved totally ineffective for cutting reeds, eliminating this as a likely prehistoric function.

At lower magnification under oblique stereomicroscopes, there are differences in the degree and location of edge rounding for the three successful harvesting tasks (stripping branches for acorns, harvesting grass and cutting reeds). Acorn stripping produced massive rounding and smoothing across each tooth of the denticulate edge in most contact with braches (Figure 18, centre). The smoothing is associated with polish visible at higher magnification under vertical incident light (Figure 18, right).

Harvesting reeds produced less edge rounding visible at lower magnification then the other tasks (Figure 21, centre), less levelling and a more uneven microtopography (Figure 21, right).

Harvesting grass produced a similar degree of edge rounding as stripping acorns, but less levelling or smoothing visible at low magnification (Figure 24, centre). The degree of polish formation was also similar (Figure 24, right). Smoothing was less developed on the reed cutting tools. Striations were most common on the acorn stripping tool.

Despite these variations, small patches of polish in the three harvesting experiments can be strikingly similar. The extent of polish development on the grass cutting sickles may be more extensive and follows surface undulations; the edge rounding and smoothing may be most extensive with acorn stripping. Further work is required to investigate the nature of polish formation on (relatively) soft rock like slate. Del Bene and Shelley (1979) noted that translocation, cohesive deposition and build-up of debris were noted as dominant mechanisms in 'polish' formation on soapstone implements (where 'polish' in this context is explicitly understood to be an additive layer).

\section{DISCUSSION}

Studies by Dubreuil (2004) identified criteria for discriminating between various grinding tasks using basalt implements. Significant variation visible at low (stereoscopic) and high (SEM) magnification was found in the morphology of the overall surface topography and the microtopography and grain surface modification. Importantly, oily vegetable processing produced marked levelling and rounding of micro-topographic edges that extended into the 'valleys' or low points in the micro-topography. In contrast, processing cereals produced a more rounded topographic features with polished homogenous zones. Grinding ochre produced even more levelling of grains and overall flattening of the surface. These patterns are similar to grinding on other very tough stones such as Banded Ironstone Formation, dolerite, granite and granophyres found in northwestern Australia (e.g. Fullagar and Wallis in press). However, softer sandstones may be unlikely to sustain similar features.

The toughest mineral in sandstone is quartz in the form of sand grains of various dimensions cemented in a finer matrix composed of other minerals usually cemented by silica, iron oxide and/or carbonates. The sand grains themselves can sustain distinctive usewear and polish as has been found on flaked quartz tools (e.g. Sussman 1988; Knutsson 1988; Fullagar 1991). Grinding of more weakly cemented sandstones will cause erosion of the quartz grains and abrasive smoothing that will potentially constrain the formation of smoothing and polish development. Hamon (2008) analysed sandstone for another range of grinding tasks observed with a stereoscopic microscope. These tasks included cereal processing, pounding and crushing, abrading and polishing, and de-fleshing and softening hide. Notably hard mineral abrasion tends to level the whole surface, but various mechanisms, including the hardness of the sandstone itself, addition of water and sand, and properties of the various materials that were ground, can account for the degree of levelling. Also notable is the observation that usewear and polish may not develop beyond a certain stage depending on how rapidly grains of sand are plucked or eroded during use.

Similar observations were documented in our study, although we suggest that the degree of overlap between usewear patterns on tools used for similar tasks and tools used for multiple tasks has been under-estimated.

Although our experiments suggest a difference between grinding seeds (like millet and oats) and pounding and grinding acorns, the archaeological grinding stones and edge-ground tools such as sickles that were used for 
multiple tasks are likely to have more variable and overlapping wear patterns unless the last episode of use was of sufficient duration to obliterate earlier tasks.

Processing other kinds of fruit, nuts, vegetables and seeds with a wider range of biochemical and mechanical properties is likely to indicate even more overlap in wear patterns, although it may well prove possible to discriminate between larger softer kernels and smaller harder seeds.

Residue analysis is therefore crucial for identifying taxonomic detail, although interpreting those residues is also complicated. We do not discuss these problems further, but one of us, Sheahan Bestel, has found that recovered phytoliths on experimental sickles do not necessarily match the harvested species! The latter is presumably caused either by contamination or by deposition of phytoliths from others species at the harvest locations.

\section{CONCLUSIONS}

Processing acorns or cereal grains can be distinguished on the basis of distinctive usewear on sandstone grinding implements. Distinctive features probably relate to the mode of use (grinding vs. pounding), properties of the sandstone (e.g. strength of cementation and grain size), polishing agents (e.g. amorphous silica content of the plants, or phytoliths) as well as the stone, moisture content and other variables (e.g. the amount of pressure or force applied).

Harvesting acorns, grass and reeds produced less distinctive usewear on hafted denticulate slate sickles than what is visible on grinding stones. Further experiments are required to control for the different actions, locations of maximum force and the usewear distribution on the implements.

Overlapping wear patterns from multiple uses are problematic and residues are needed to identify details of processed materials.

\section{ACKNOWLEDGEMENTS}

This paper was presented at the 19TH CONGRESS OF THE INDO-PACIFIC PREHISTORY ASSOCIATION $\left(29^{\text {th }}\right.$ November - 5th December 2009), at the Vietnam Academy of Social Sciences Conference Centre, Hanoi, Vietnam. We thank the organisers (including the Vietnam Academy of Social Sciences and the Vietnam Institute of Archaeology) and participants for questions and comments. We are particularly grateful to Alfred Pawlik and Xingcan Chen, who provided very useful comments that have improved this paper. We thank La Trobe University for facilitating the research, and organisers and participants at the IPPA conference in Hanoi, 2009.

\section{REFERENCES}

Chen, W. 2002. Nongye Kaogu. Beijing: Wenwu Press.

Cunnar, G. 2007. The Production and Use of Stone Tools at the Longshan Period Site of Liangchengzhn, China. Unpublished Ph.D. dissertation, Department of Anthropology, Yale University, New Haven.

Dubreuil, L. 2004. Long-term trends in Natufian subsistence: a use-wear analysis of ground stone tools. Journal of Archaeological Science 31: 1613-29.
Fullagar, R. 1991. The role of silica in polish formation. Journal of Archaeological Science 18:1-25.

Fullagar, R. and Wallis, L. In press. Usewear and phytoliths on bedrock grinding patches, Pilbara, north-western Australia. The Artefact 35(2012).

Hamon, C. 2008. Functional analysis of stone grinding and polishing tools from the earliest Neolithic of north-western Europe. Journal of Archaeological Science 35: 1502-20.

Knutsson, K. 1988. Patterns of Tool Use. Scanning electron microscopy of quartz tools. Societas Arcjaeologica Upsaliensis: Uppsala. Aun 10.

Liu, L. 2008. Zhongguo shiqian de nianmo shiqi, jianguo caiji, dingju ji nongye qiyuan (Grinding stones, nut collection, and origins of sedentism and agriculture in prehistoric China). In "Essays for the Celebration of Ping-ti Ho's 90th Birthday" (ed.), He Ping-ti Xiansheng Jiushi Shouqing Wenji (Essays for the Celebration of Ping-ti Ho's 90th Birthday), pp. 105-132. Xi'an: Sanqin Press.

Liu, L., J. Field, R. Fullagar, S. Sheahan Bestel, Xingcan Chen \& Xiain Ma. 2010a. What did grinding stones grind? New light on Early Neolithic subsistence economy in the Middle Yellow River Valley, China. Antiquity 84: 816-833.

Liu, L., J. Field, R. Fullagar, Chaohong Zhao, Xingcan Chen and Jincheng Yu. 2010b. A functional analysis of grinding stones from an early Holocene site at Donghulin, North China. Journal of Archaeological Science 37: 2630-2639.

Owen, D. 2007. An exercise in experimental archaeology on Chinese stone spades. Bulletin of the Indo-Pacific Prehistoric Association 27: 87-92.

Song, Z. 1997. Shiqian shiwu de jiagong jishu - lun moju yu chujiu de qiyuan (Food processing techniques in prehistory - on the origins of grinding tools, mortars and pestles). Nongye Kaogu 3, 187-195.

Sussman, C. 1988. A Microscopic Analysis of Use-wear and Polish on Experimental Quartz Tools. Oxford: BAR International Series 395.

Wu, J. 1986. Shiqi shidai de shimopan (Grinding slabs in the Neolithic period). Shiqian Yanjiu 1 (2) 46-54. 

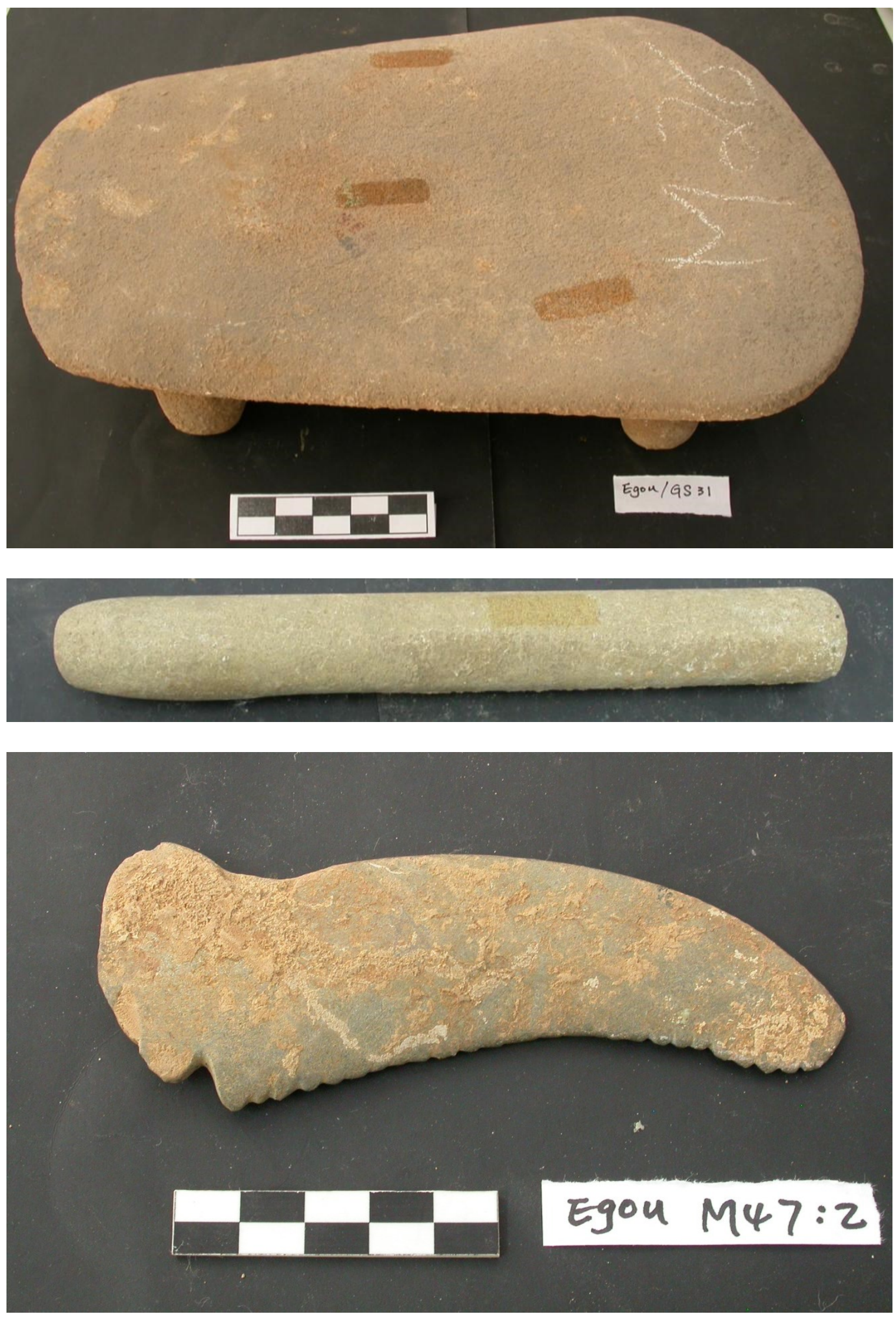

Figure 1: Lower (Mopan) and upper (Mobang) Peiligang grinding stones and sickle. 


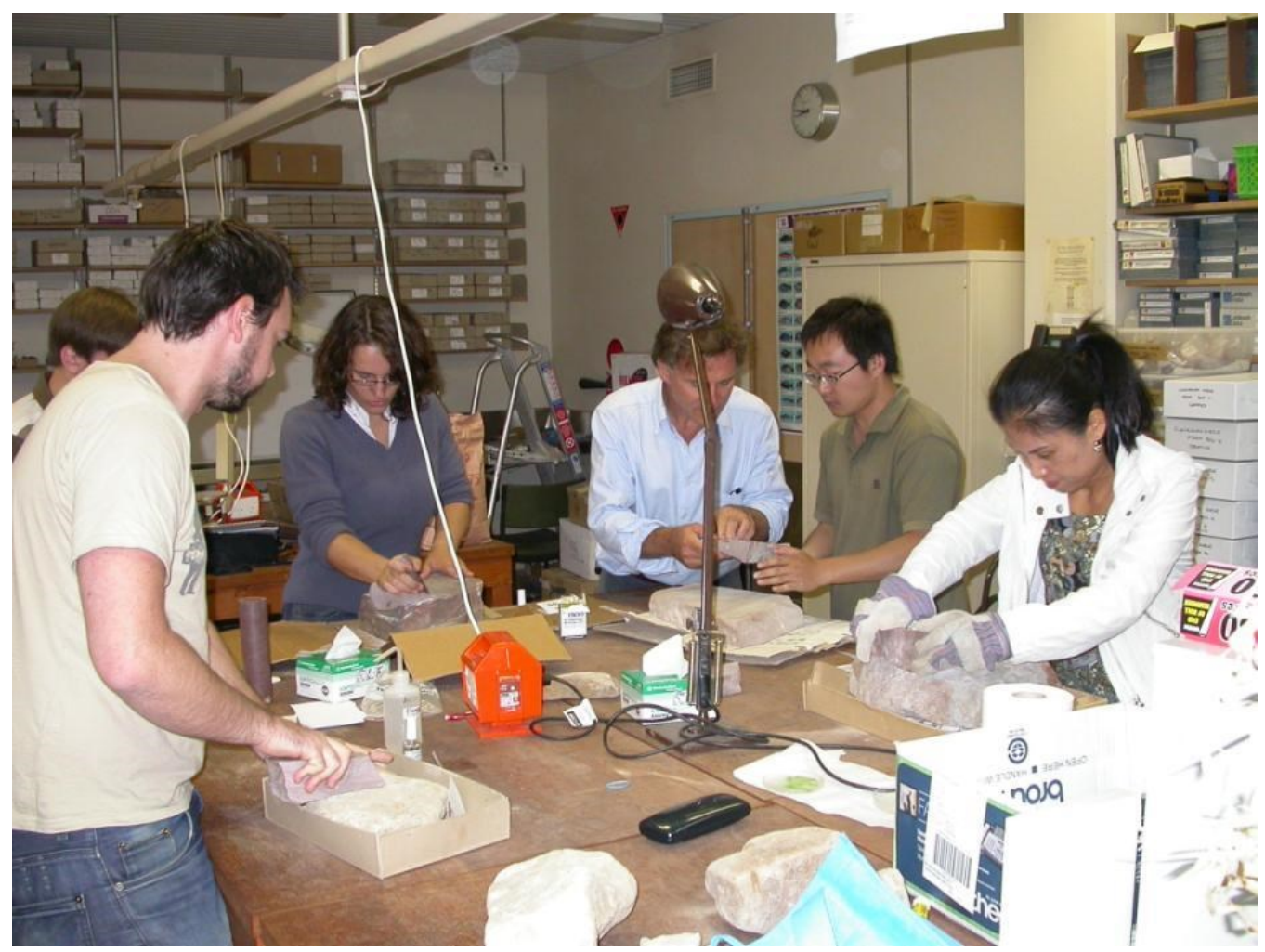

Figure 2: Workshop experiments at La Trobe University.

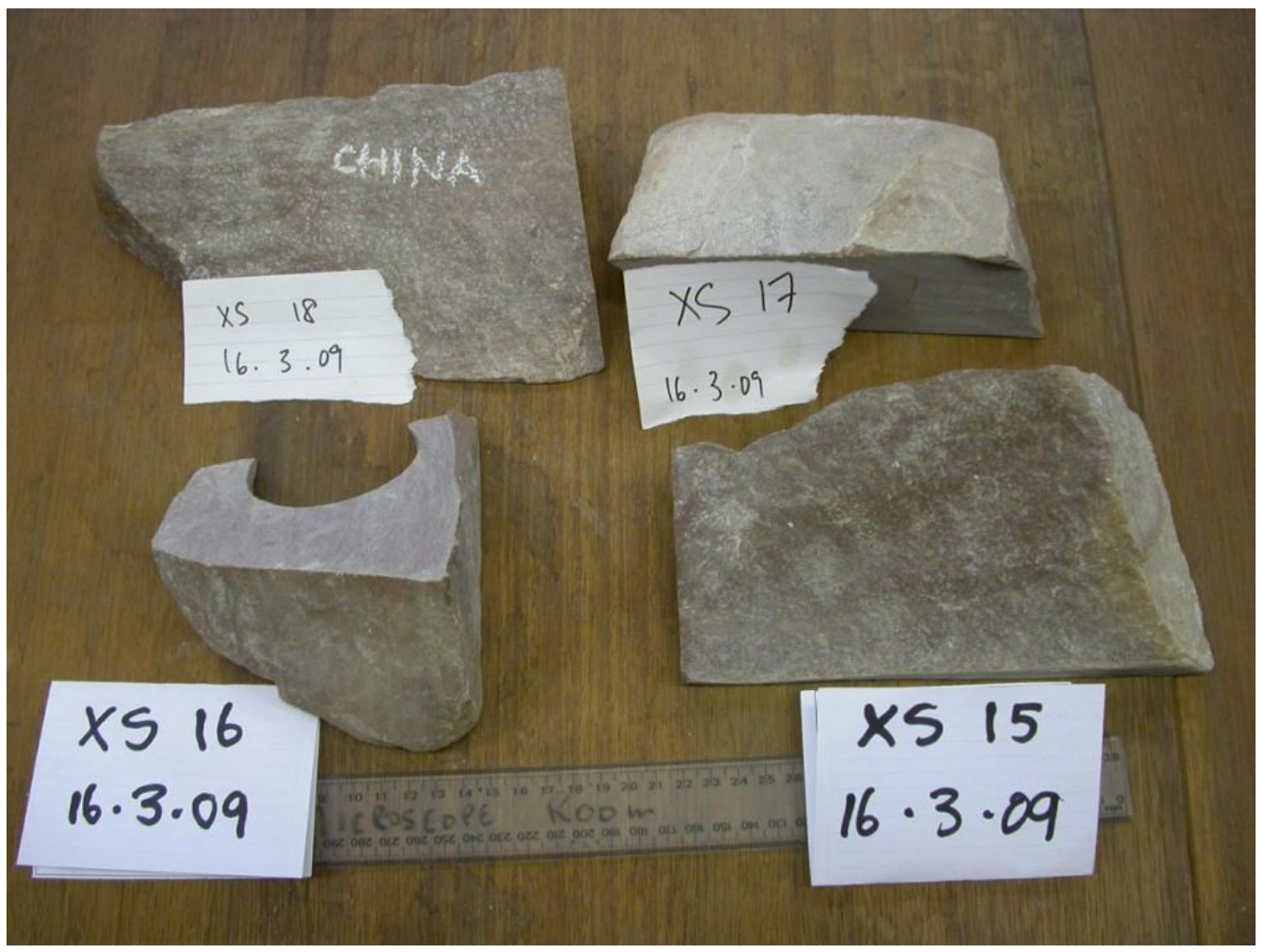

Figure 3: Experimental handstone rocks 


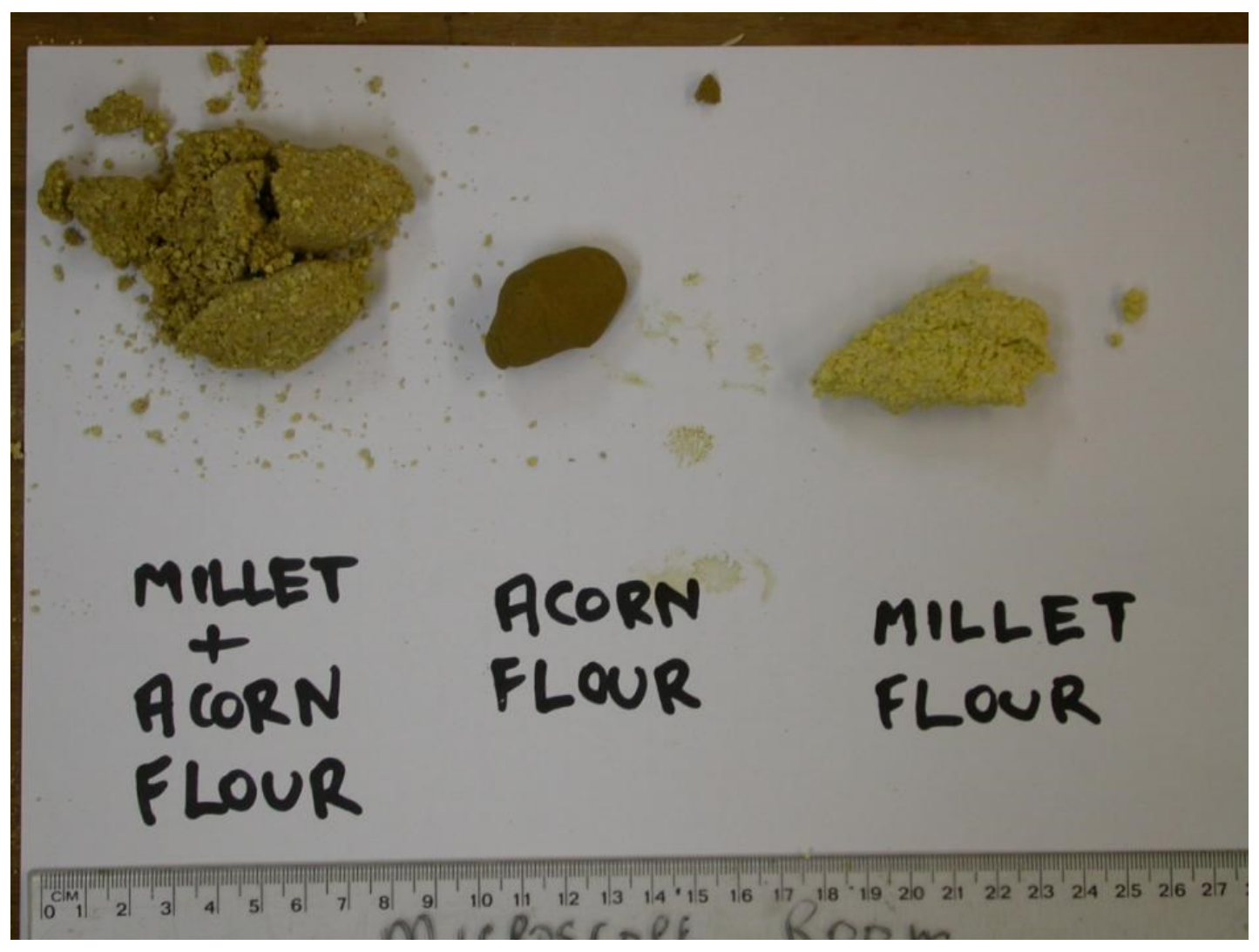

Figure 4: Plant food after grinding.

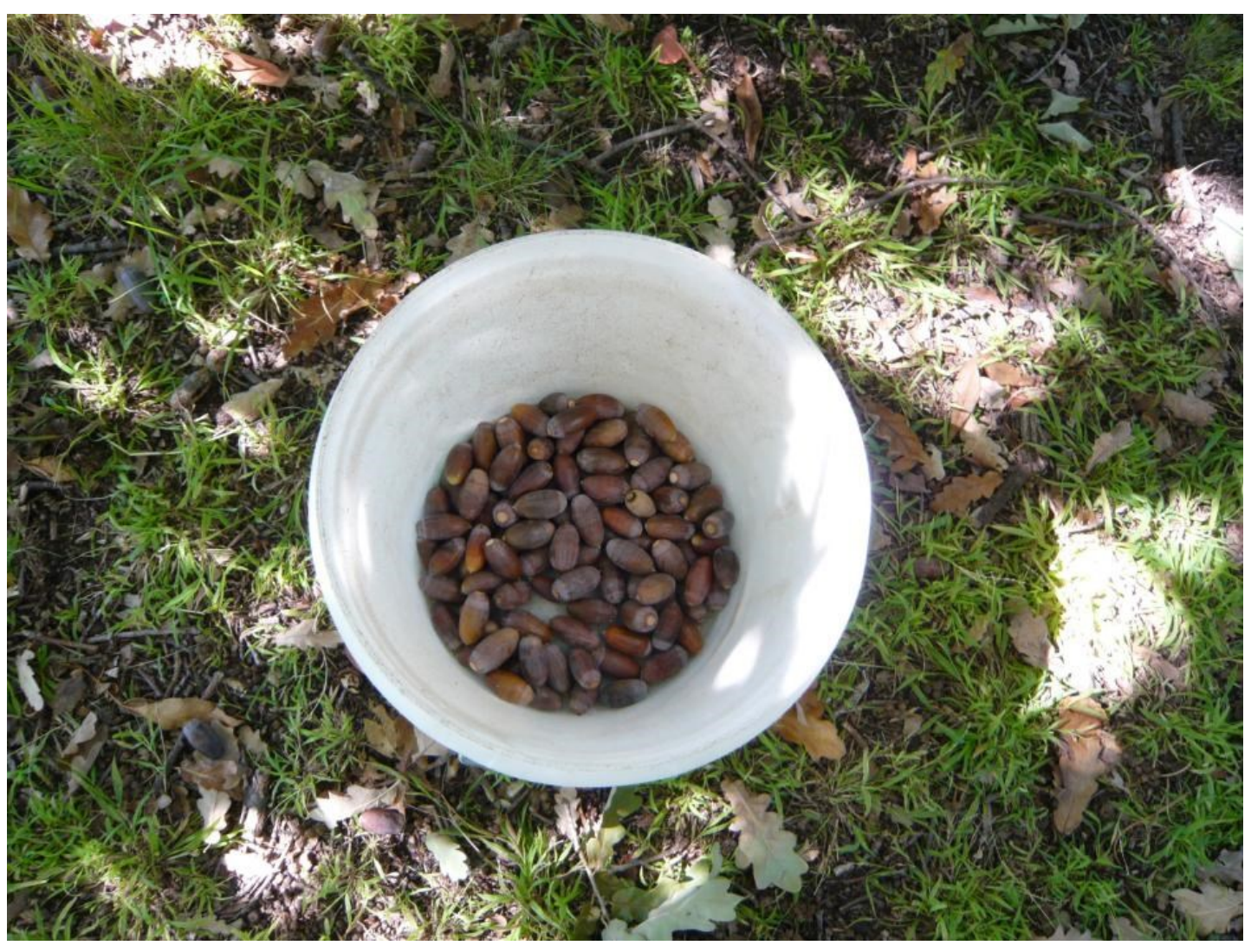

Figure 5: Acorns harvested and soaked in a bucket. 


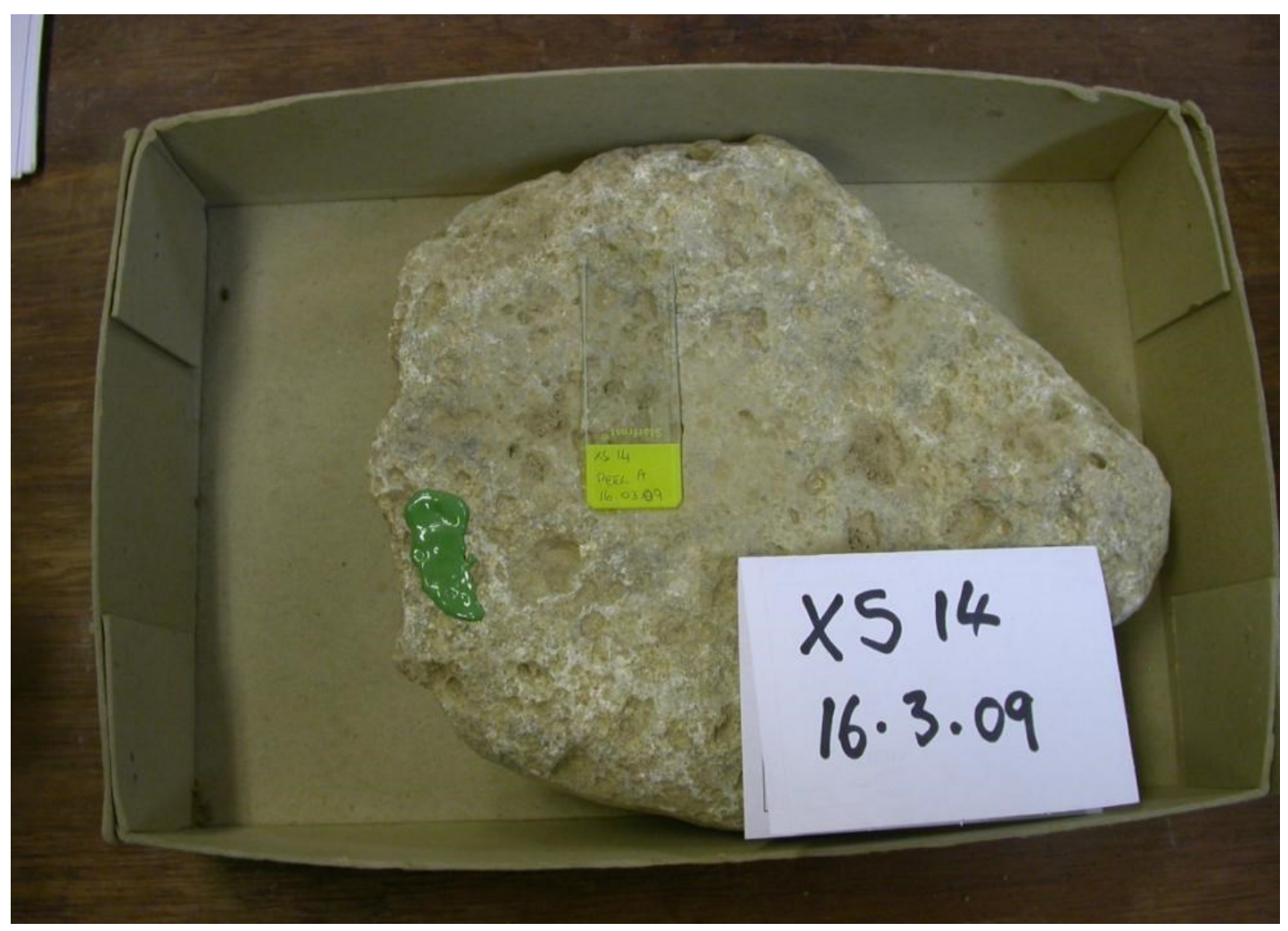

Figure 6: Lower stone XS14 made of tuff showing PVS Peel A (after cleaning and before use).

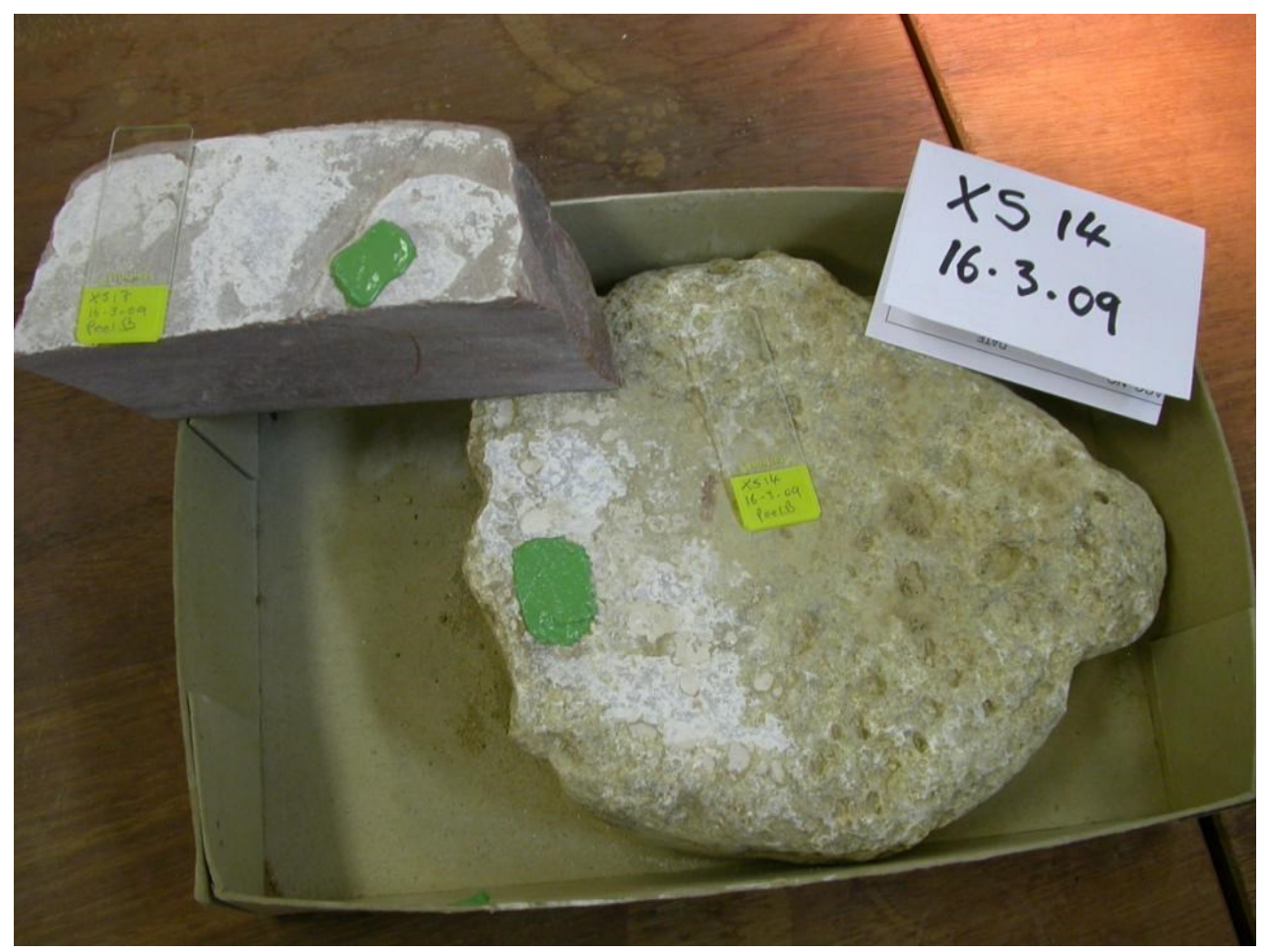

Figure 7: Lower stone XS14 made with of tuff and XS17 made of sandstone showing PVS Peel B series. 


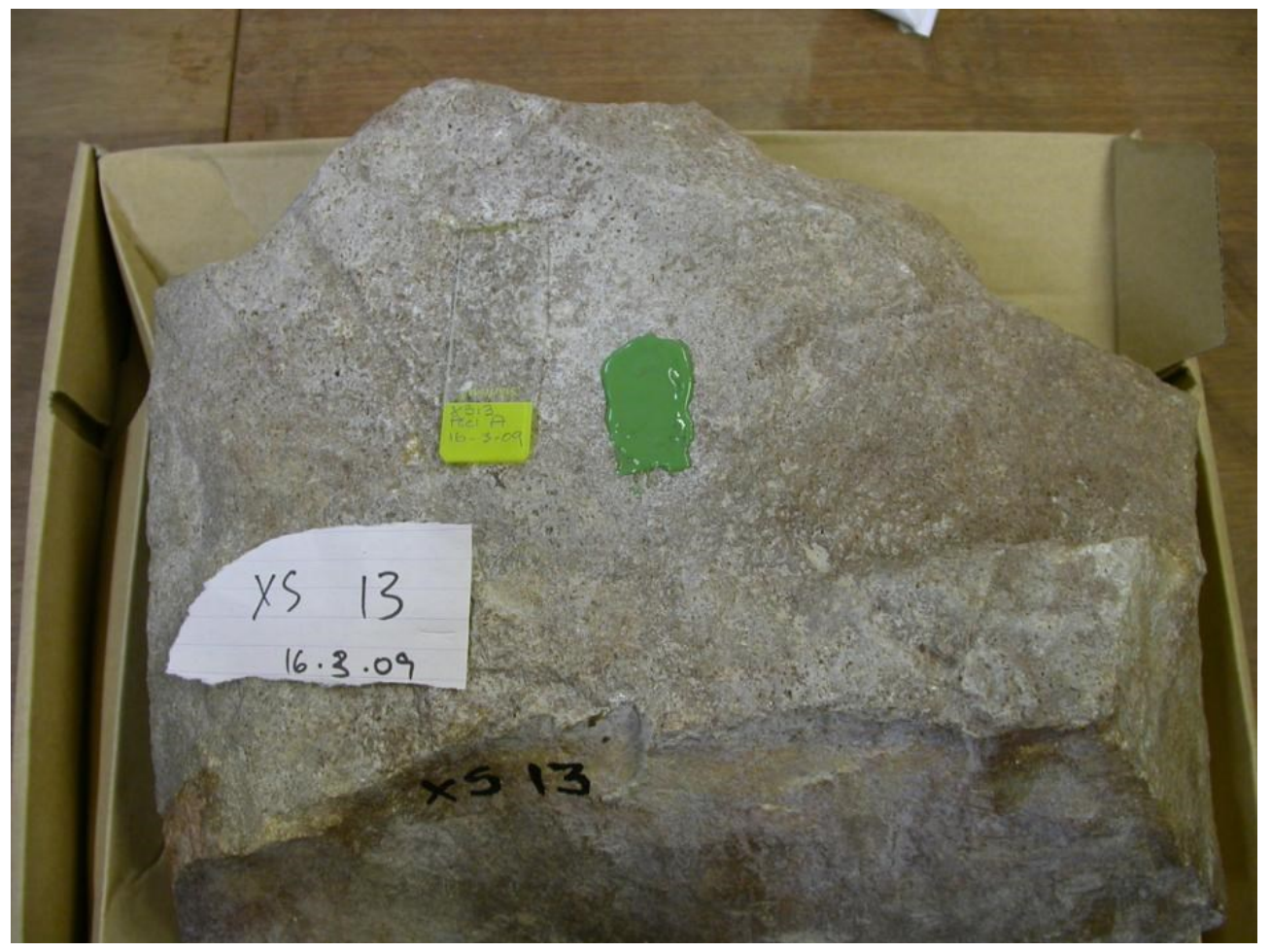

Figure 8: Lower stone XS13 made of sandstone showing PVS Peel A after cleaning and before use.

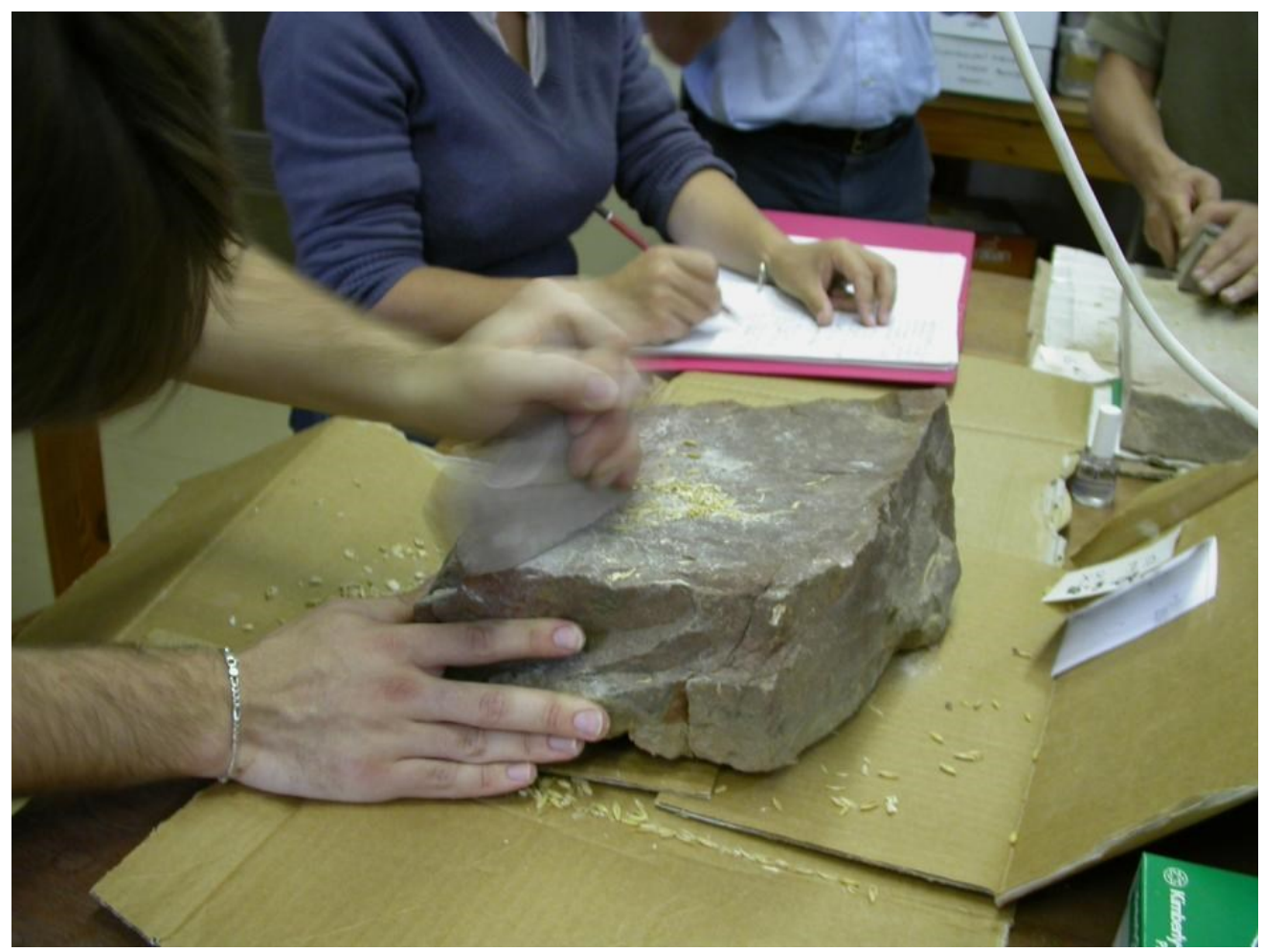

Figure 9: Lower stone XS13 sandstone and XS15 handstone in action. 

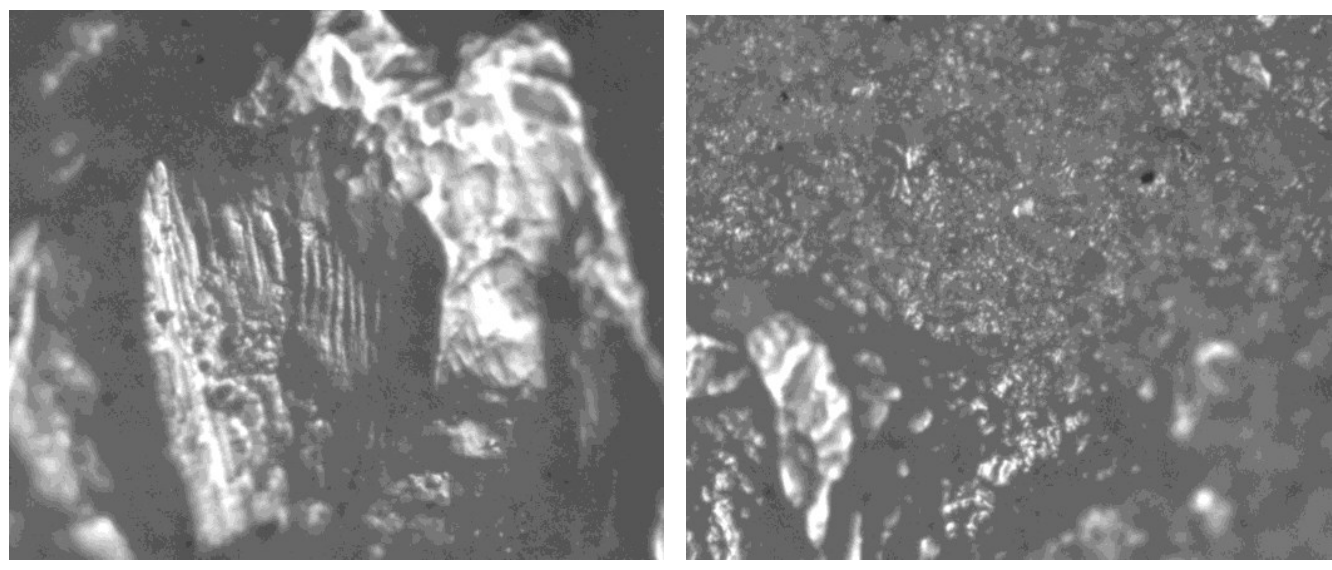

Figure 10: PVS Peel A of lower stone XS13 (unused). Width of Field is 0.3mm. Left: fresh quartz crystal features. Right: initial abrasive smoothing.
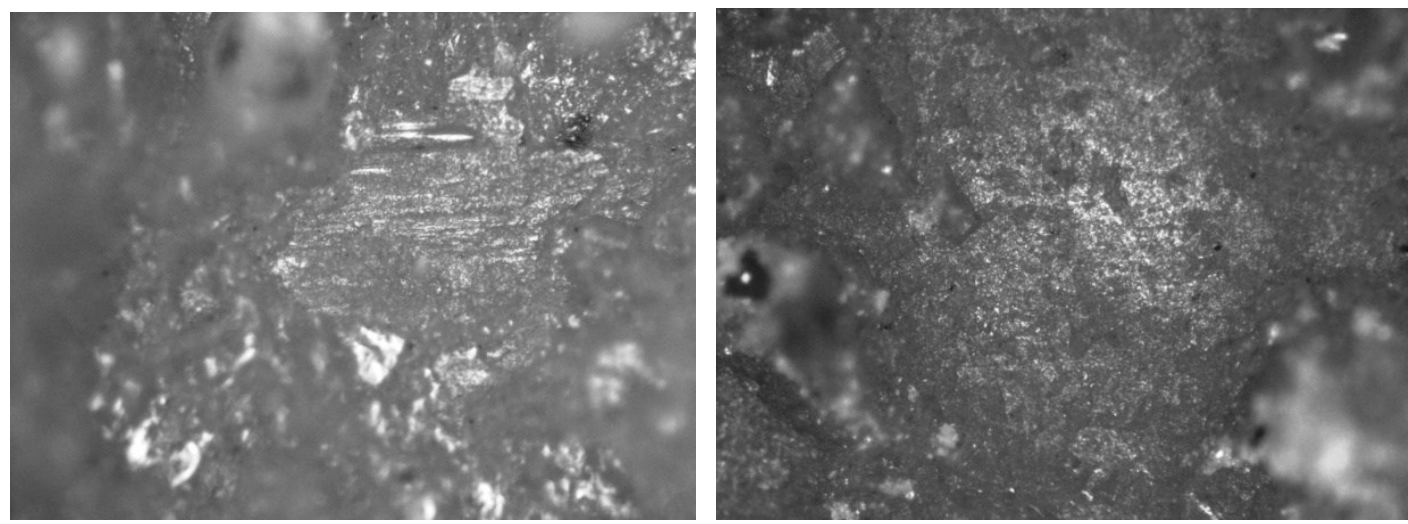

Figure 11: PVS Peels of lower stone XS13. Width of Field is 0.3mm. Left: Peel B, after grinding stone on stone for 15 minutes. Right: Peel C, after grinding oats (with husks).
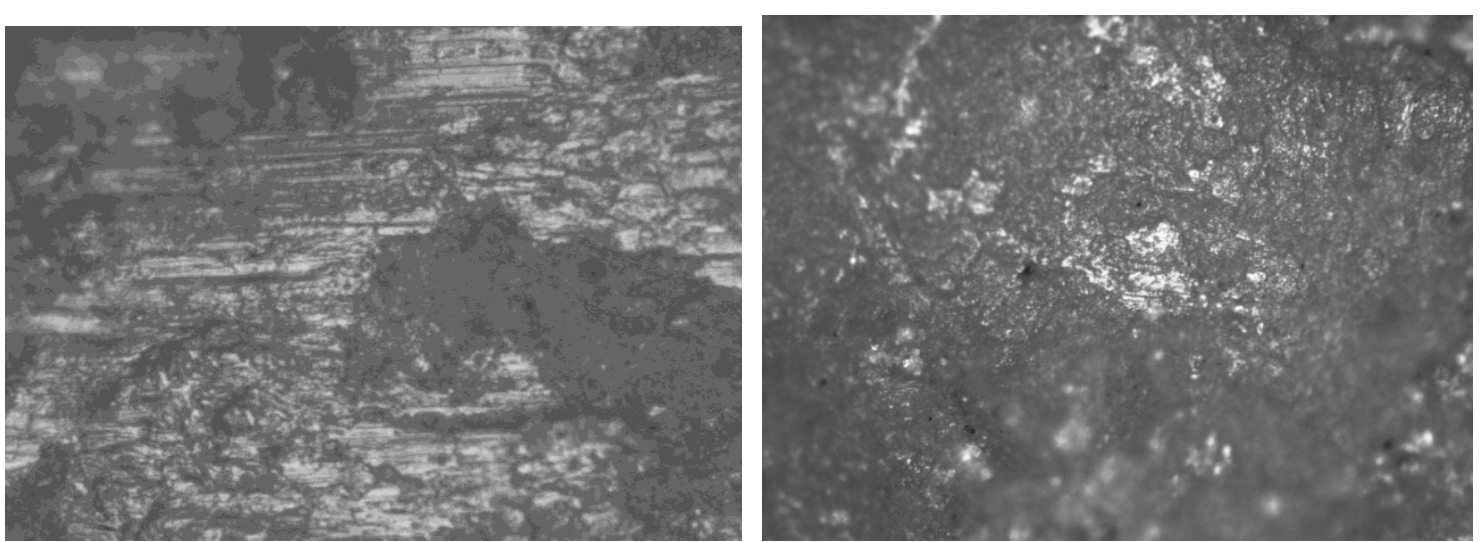

Figure 12: PVS Peels of lower stone XS13. Width of Field is 0.7mm. Left: Peel F, after stone polishing for 8 hours. Right: Peel $G$, after pounding acorns with husks. 

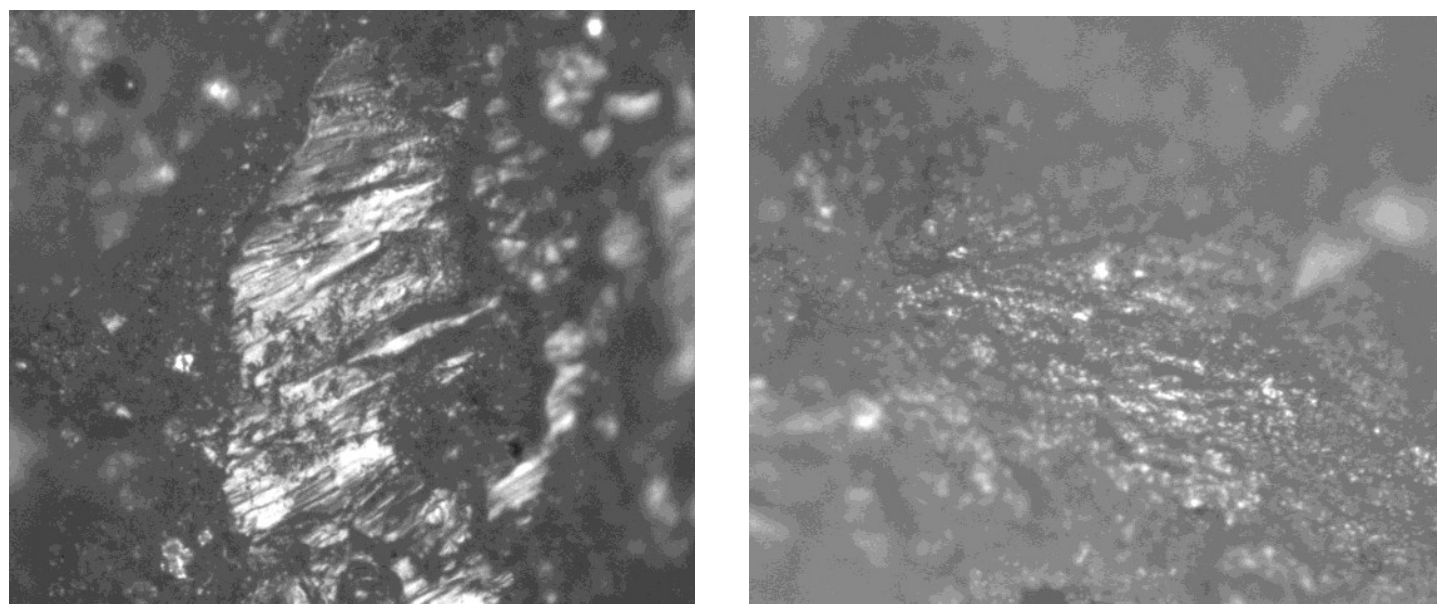

Figure 13: PVS Peel E of lower stone XS13 E, after grinding rock on rock, oats (with husks) and millet (with no husks). Width of Field is $0.7 \mathrm{~mm}$. Left: Striations (from stone grinding) on and adjacent to a quartz crystal. Right: polish and striations from grinding oats and millet.
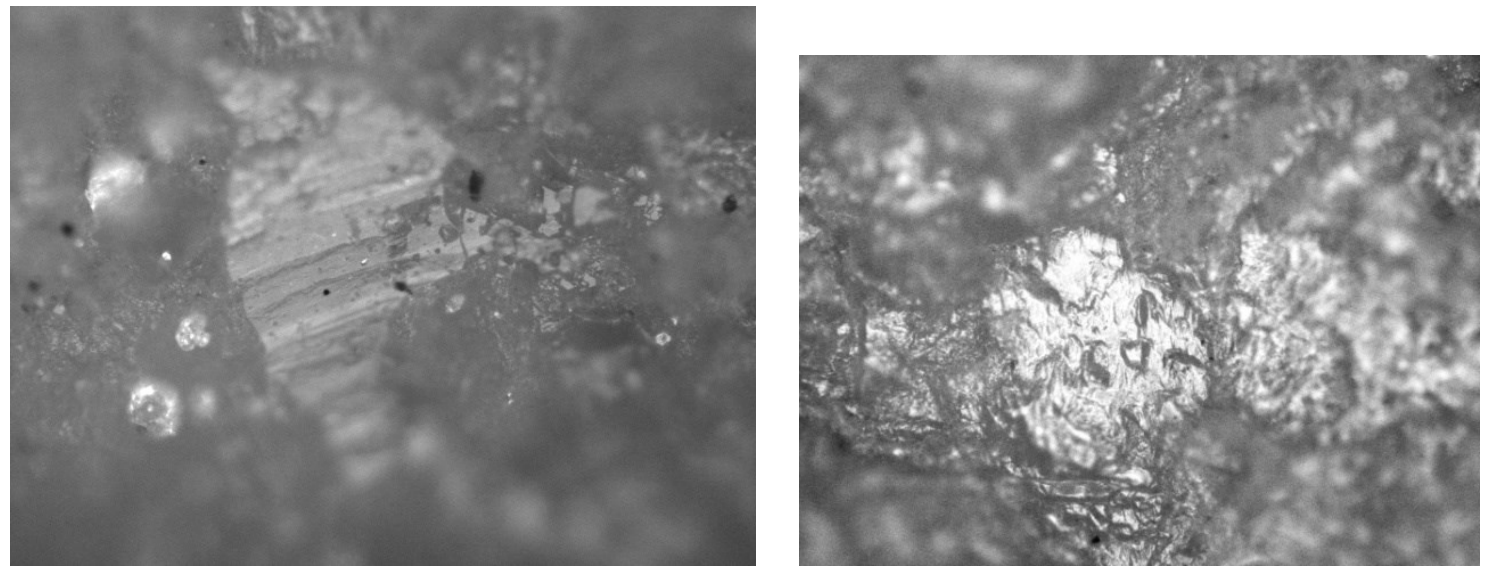

Figure 14: PVS Peels of lower stone XS12, after grinding and pounding acorns. Left: Peel H, showing crushing on fresh fracture surface of quartz. Width of Field is $0.7 \mathrm{~mm}$. Right: Peel H, showing undulating polish and shallow pitting. Width of Field is $0.3 \mathrm{~mm}$.
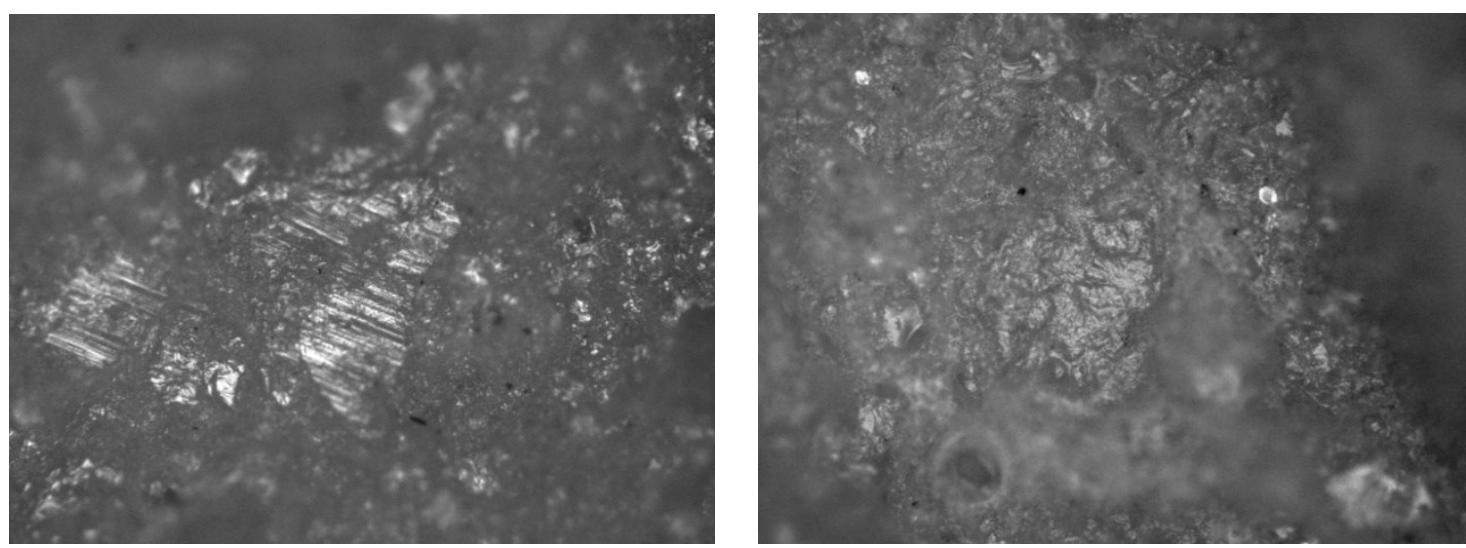

Figure 15: Left: PVS Peel H of lower stone XS13 after pounding acorns on previously ground surface. The striations are from the stone grinding. Width of Field is 0.7mm. Right: PVS Peel H of lower stone XS14 after pounding acorns. Note the absence of striations. Width of Field is $0.73 \mathrm{~mm}$. 


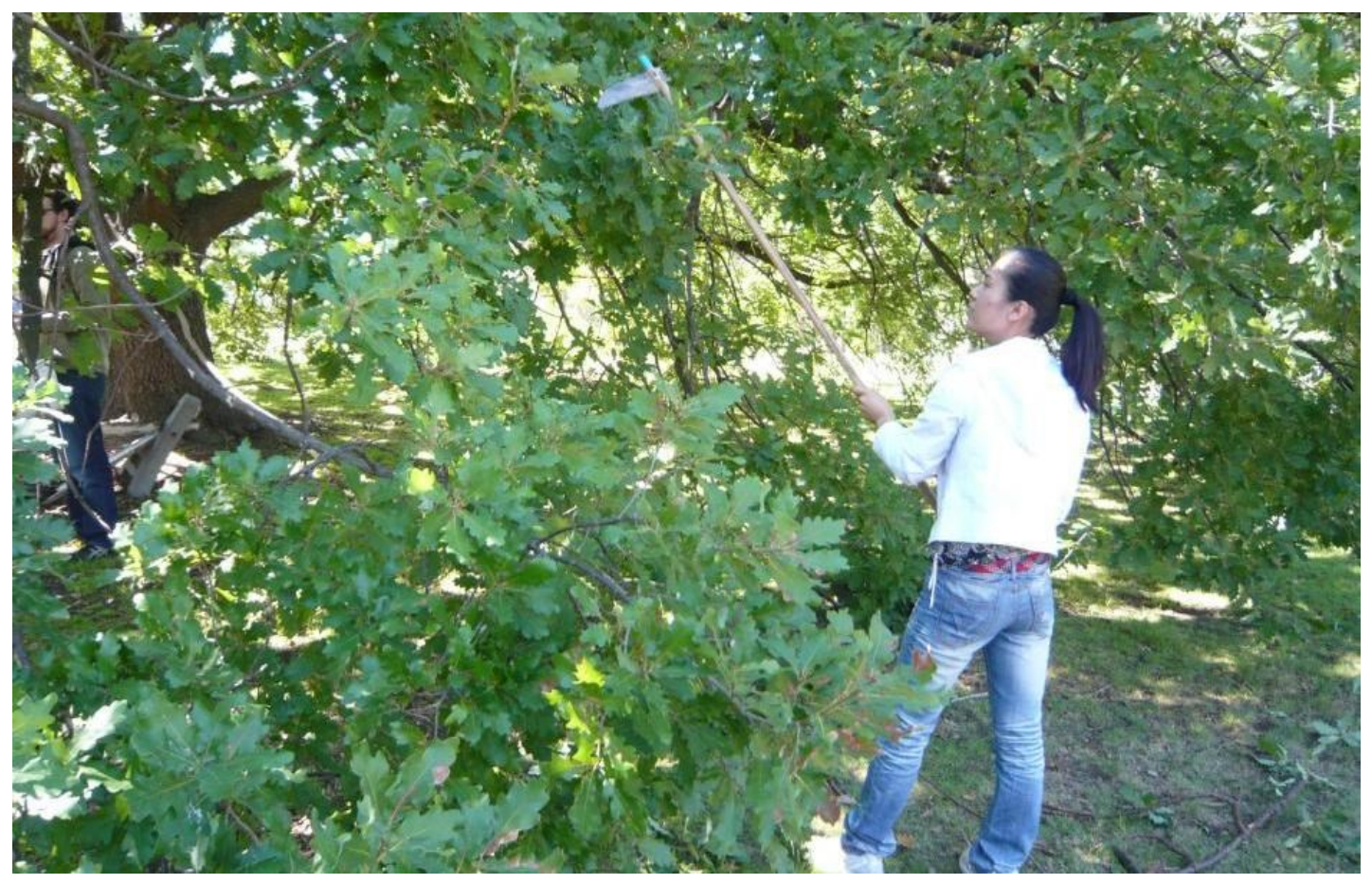

Figure 16: Harvesting acorns with hafted denticulate sickle XSK01.

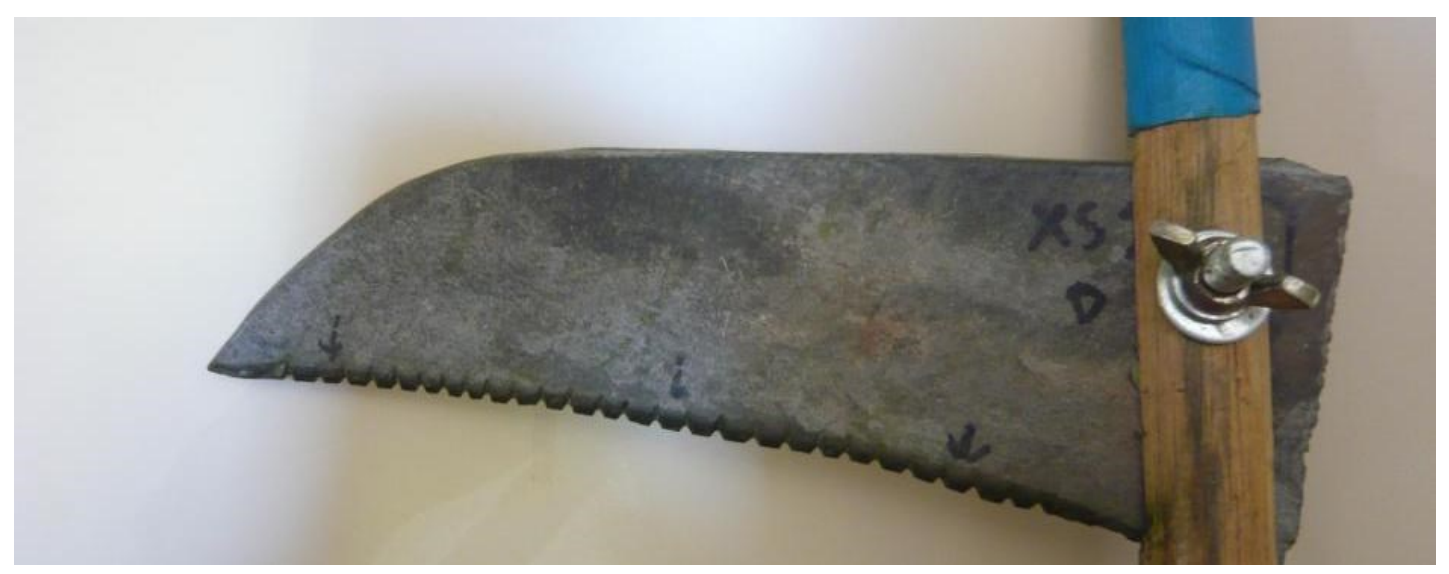

Figure 17: Experimental sickle for harvesting Quercus sp. acorns.
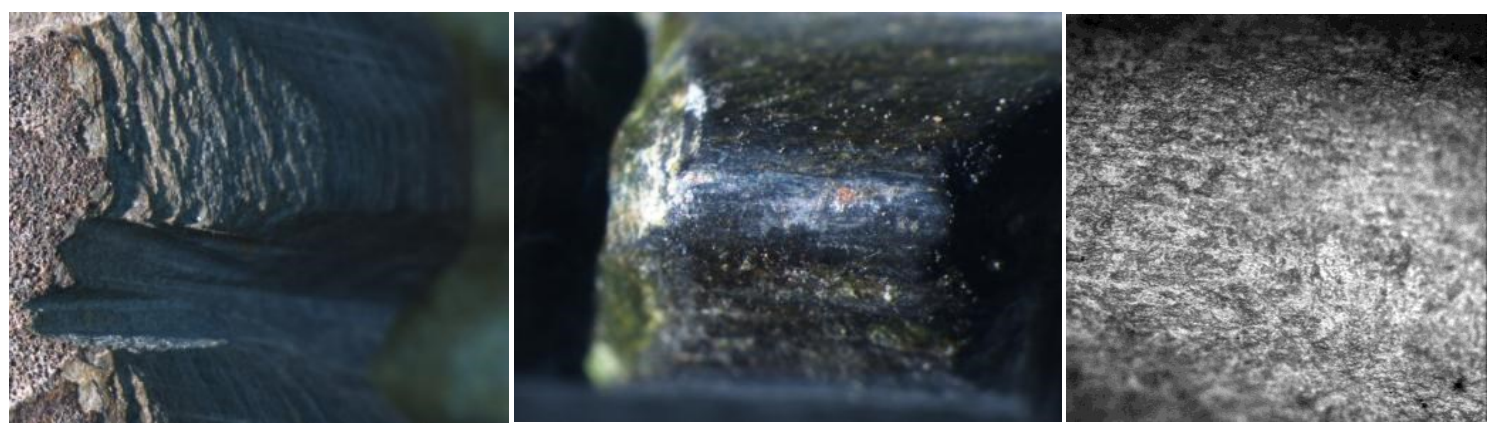

Figure 18: Experimental hafted denticulate sickle XSK01 edge. Width of slate is about 3mm. Left: Manufacturing marks. Centre: Edge rounding after harvesting acorns (end view). Width of slate is about 3mm. Right: Usewear after harvesting acorns (side view). Width of view is $0.7 \mathrm{~mm}$. 


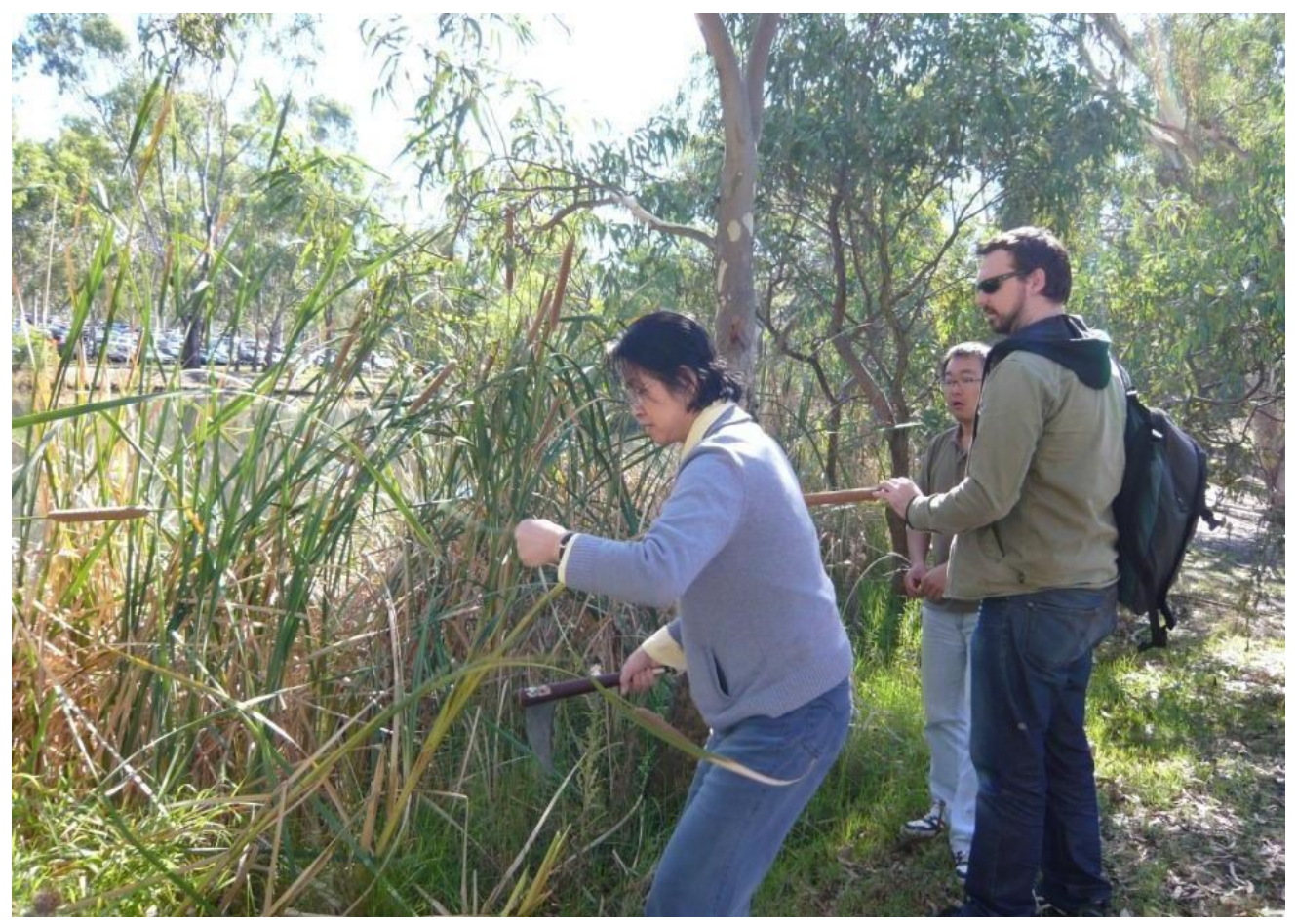

Figure 19: Harvesting Typha reeds with hafted denticulate sickle XSK02.

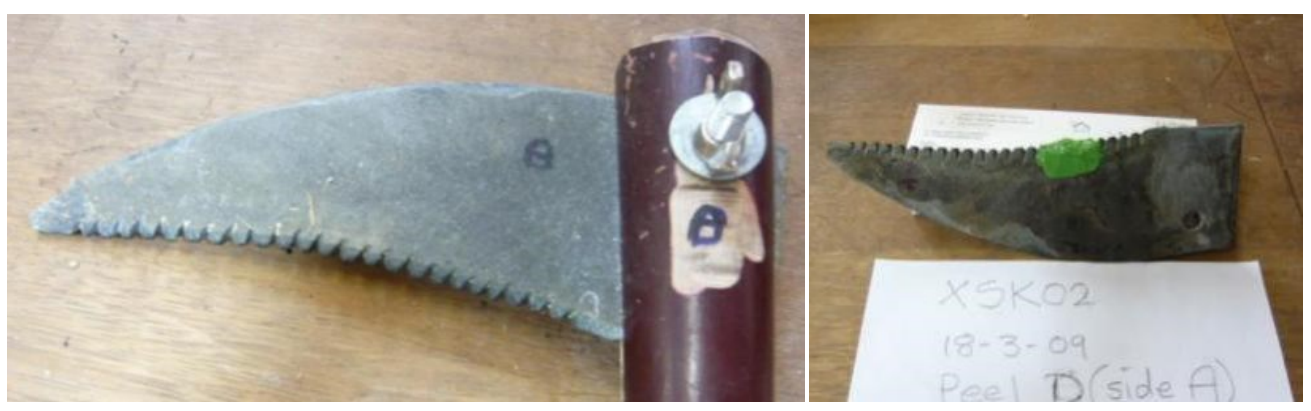

Figure 20: Left: Experimental hafted denticulate sickle XSK02 for harvesting Typha sp. reeds. Right: Experi-mental hafted denticulate XSKO2 sickle detached from handle for documenting traces of use.
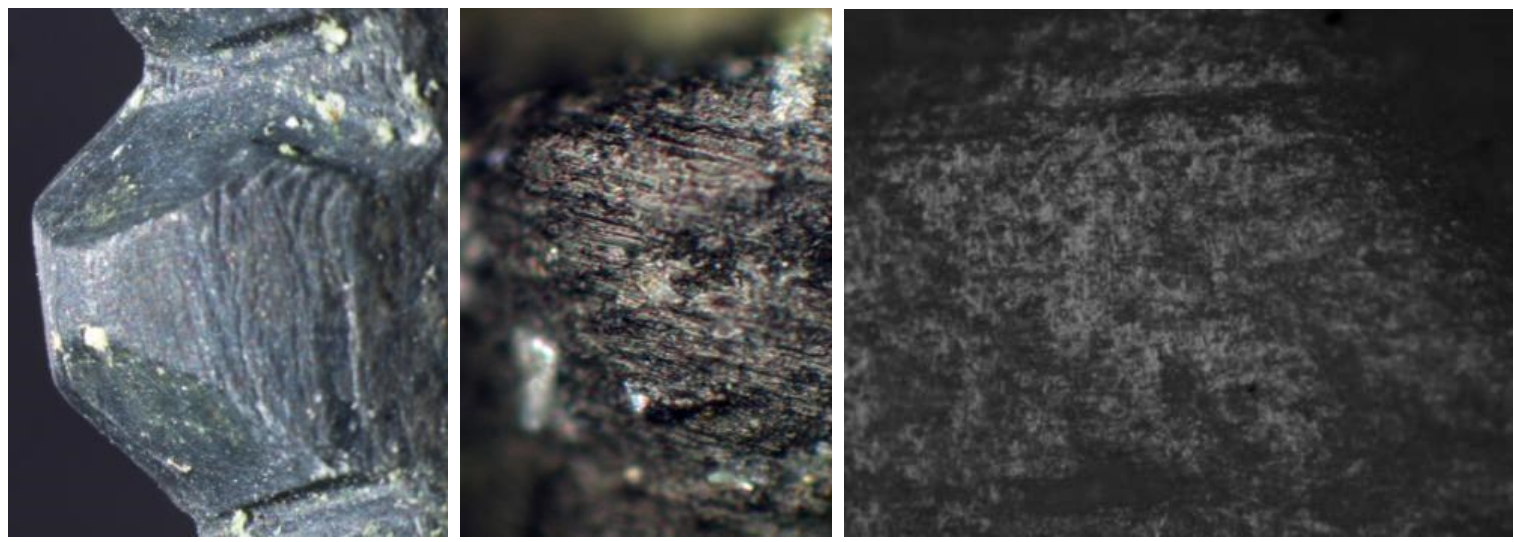

Figure 21: Experimental hafted denticulate sickle XSK02 edge. Width of slate is about 3mm. Left: Manufacturing marks. Centre: Edge rounding after harvesting Typha sp. reeds (end view). Width of slate is about 3mm. Right: Usewear after harvesting Typha sp. reeds (side view). Width of view is $0.7 \mathrm{~mm}$. 


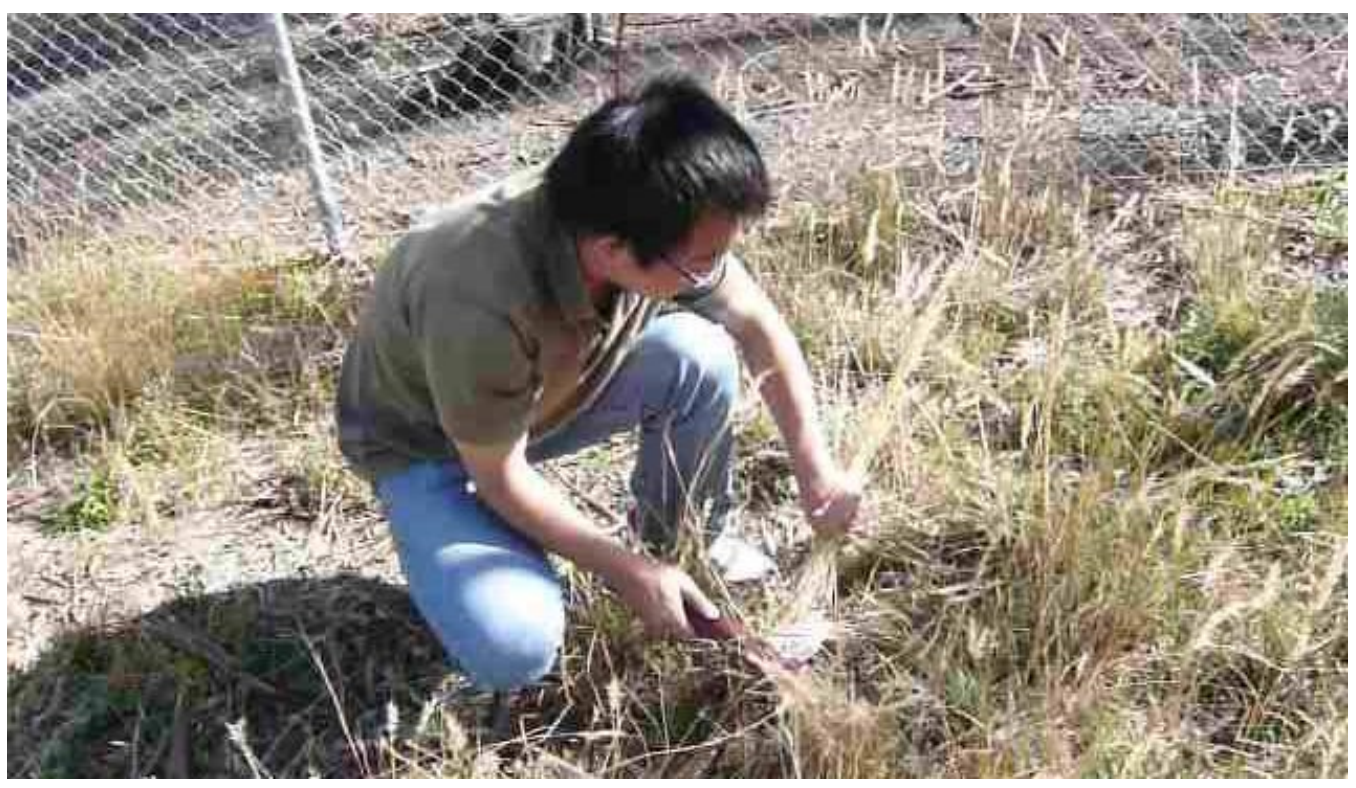

Figure 22: Harvesting grass with experimental hafted den-ticulate Sickle XSK03.

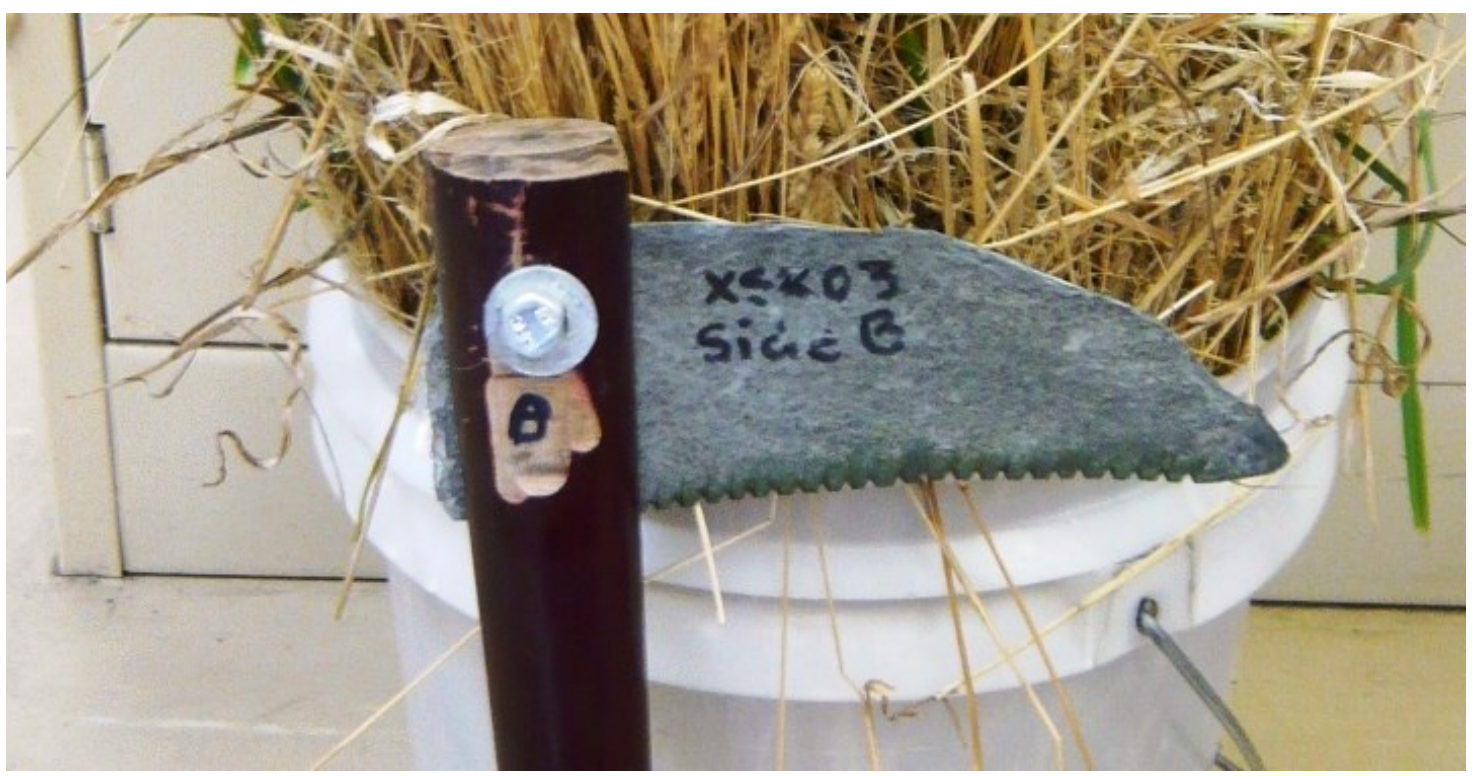

Figure 23: Experimental hafted denticulate sickle XSK03 for harvesting grass
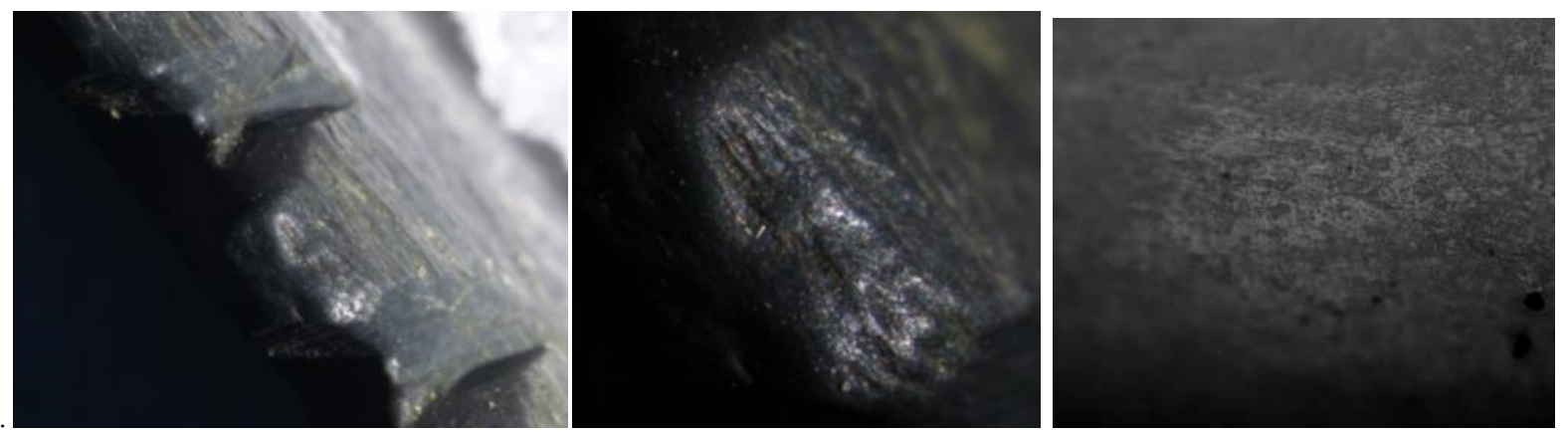

Figure 24: Experimental hafted denticulate sickle XSK03 edge. Width of slate is about 3mm. Left: Manufacturing marks. Centre: Edge rounding after harvesting grass (end view). Width of slate is about $3 \mathrm{~mm}$. Right: Usewear after harvesting grass (side view). Width of view is $0.7 \mathrm{~mm}$ 